- Little research has been undertaken to assess change in dentistry.

- This study has identified that a considerable amount of reported change has taken place in GDPs' work patterns in recent years.

- Younger practitioners, those with postgraduate qualifications and those earning more than $20 \%$ of their income from private practice reported higher levels of change.

\title{
The prevalence and nature of recent self- reported changes in general dental practice in a sample of English general dental practitioners
}

\author{
R. Watt, ${ }^{1}$ P. McGlone, ${ }_{1}^{2}$ D. Evans, ${ }_{1}^{3}$ S. Boulton, ${ }_{1}^{4}$ J. Jacobs, ${ }_{1}^{5}$ S. Graham, ${ }_{1}^{6}$ T. Appleton, ${ }_{1}^{7}$ S. Perry ${ }^{8}$ and A. Sheiham ${ }^{9}$
}

\begin{abstract}
Objective To determine the extent and types of change in seven domains of dental practice in a sample of English general dental practitioners (GDPs).
\end{abstract}

Methods A postal questionnaire was sent to $561 \mathrm{GDPs}$ on the dental lists of three health authorities in diverse regions of England. Information collected included demographic details on personal and practice characteristics, self-rating of amount of change in the seven domains of practice and factors influencing change.

Results The response rate was 60\%. Fifty-six per cent of the sample were under 40 years old. Over a third of respondents reported 'changing a lot or completely' certain clinical activities, practice management arrangements and practice amenities. The highest selfreported level of change was in clinical activities. Of the GDPs who reported changing their clinical activities, 56\% reported an increase in preventive care, followed by crown and bridge (44\%), periodontics (44\%) and endodontics (43\%). Practice management rated second in the mean rank scores for self-reported change. The main changes reported were the introduction of computer systems and employment of practice managers. A sizeable percentage (66\%) reported increasing the amount of information they provided to patients and the time spent discussing care. Quality assurance activities were the area of practice least likely to have changed over a 5 -year period. Over half the sample reported not being involved in any quality assurance activities in the previous 5 years. Those respondents who were younger, had a postgraduate qualification and earned more than $20 \%$ of their income from private practice reported higher levels of change. Conclusions General dental practitioners' work patterns are dynamic and appear to be responding to changing needs and demands on their

\footnotetext{
${ }^{1 *}$ Reader, ${ }^{2}$ Research Fellow, ${ }^{9}$ Professor, Department of Epidemiology and Public Health, University College London; ${ }^{3}$ Consultant in Dental Public Health, Department of Dental Public Health, North Tyneside Primary Care Trust, Benfield Road, Newcastle upon Tyne; ${ }^{4}$ Consultant in Dental Public Health, Department of Dental Public Health, Coventry Primary Care Trust, Greyfrairs Lane, Coventry; ${ }^{5}$ Consultant in Dental Public Health, Department of Dental Public Health, Islington Primary Care Trust, London; ${ }^{6}$ GDP, North Shields, Tyne and Wear; ${ }^{7}$ GDP, Queens Road, St Peter Port, Guernsey; ${ }^{8}$ GDP, Westmount Road, Eltham, London *Correspondence to: R. Watt, Department of Epidemiology and Public Health, University College London WC1E 6BT

Email:r.watt@ucl.ac.uk
}

\section{Refereed paper}

Received 5.03.03; Accepted 11.11.03

doi:10.1038/sj.bdj.4811720

๑ British Dental Journal 2004; 197: 401-405 service. The main changes were in the types of clinical procedures being carried out. The low prevalence of changes reported in auditing and peer review activities needs to be investigated further.

In recent years the demands for change within the NHS have steadily increased. Publication of the NHS Plan set out an agenda for reform to modernise the system and improve quality of care. ${ }^{1}$ In dentistry the pressures for change are also mounting. ${ }^{2}$ The recently published NHS Dentistry: Options for Change sets out a radical and far reaching agenda for taking NHS dentistry forward within a modernised NHS. ${ }^{3}$ Pilot schemes across the country have been established to evaluate the proposed changes. However detailed implementation strategies necessary to support general dental practitioners (GDPs) in achieving these changes have not yet been formulated.

There is a paucity of research on change in dentistry. It is necessary therefore, to consider the research that has been undertaken with medical practitioners to gain some insight into the factors influencing change and the adoption of new practices and techniques. Many of these studies have been undertaken in the context of adopting an evidence-based approach to clinical medical practice. They have identified a complex interaction between the individual, where they work, and external factors that affect the implementation and adoption of new practices. ${ }^{4}$ For example, three frequently mentioned reasons for change in clinical medical practice have been identified as organisational, continuing education and contact with professionals. ${ }^{5}$ A number of interrelated factors affect adoption of evidence-based practice. The most important were the presence of innovative partners and fund-holding status. ${ }^{6}$ Characteristics of US paediatricians who had adopted innovations included: they had board certification; group rather than solo practice; involved in teaching; read medically related publications; had an academic appointment and they were younger. ${ }^{7}$

In dentistry, a number of studies on dental treatments and service provision give some indication of factors likely to affect change in dental practice. Many of the influences on dentists were similar to those influencing doctors. Personal factors, including age of dentist and attitude to the adoption of specific techniques influence change. ${ }^{8-12}$ Scepticism of the evidence is a reason why dental practitioners did not use fissure sealants as a preventive measure in general dental practice. ${ }^{13}$ Involvement in continuing education and contact with dental colleagues have been shown to 
be important influences on treatment decisions. ${ }^{8-10}$ Patients' demands are also an important influence on clinical decision making. ${ }^{14-17}$ Finally, the practice environment and other organisational factors such as degree of delegation to team members have been related to the adoption of specific practices. ${ }^{18,19}$

The objective of this study was to measure the extent and nature of recent self-reported change in a sample of English GDPs. In addition factors influencing change were also assessed.

\section{METHODS}

The study employed a combination of quantitative and qualitative research methods. After an initial phase of development and piloting, a quantitative questionnaire survey was undertaken with a sample of GDPs in three widely dispersed locations across England. The questionnaire survey was followed up with an in depth qualitative investigation on two groups of practitioners; changers and non-changers. This paper reports the results of the postal questionnaire survey.

\section{Questionnaire development}

Based upon a review of relevant policy documents, and discussions with a variety of GDPs and researchers, seven domains of dental practice were identified for inclusion within the questionnaire. These were selected to ensure that a wide range of domains of practice were included to capture the diverse range of relevant changes that practitioners may have made. The seven domains of practice were:

- Clinical activities such as restorative dentistry and endodontics, prosthetics, oral surgery, orthodontics, preventive care and use of new dental materials and techniques.

- Practice management: employment of practice manager, computerisation of patient records and management systems.

- Quality assurance: involvement in audit or peer review, use of the self assessment manual and standards (SAMS) document.

- Staff development: organisation of staff meetings and training.

- Communication with patients: information given to patients (verbal or written).

- Postgraduate training: attendance at post-graduate courses, membership of study clubs.

- Practice amenities: improvements in facilities and equipment.

The self-complete questionnaire collected information on the following areas: respondents' personal and professional characteristics; practice type and patient profiles; extent and nature of self reported change in the seven domains of practice over the previous five years; and factors influencing any changes made.

Self reported change was measured using a standardised fourpoint Likert scale. In each domain of practice, respondents were asked to report whether they had changed a little, a lot, completely or not all. A five-year time frame was used to aid recall, although the dentists were also asked about any changes that had taken place prior to five years ago.

The questionnaire was first piloted with 100 GDPs. Through this process a variety of questions were modified or excluded. The reliability of the final questionnaire was assessed with a group of nine dentists. Good consistency was achieved. A validity test on the final questionnaire was carried out using a triangulation method; data collected in the questionnaire was compared with the accounts of the dentists interviewed in the final stage of the study. ${ }^{20}$

\section{Study sample}

The self-complete questionnaires were posted to all GDPs on the dental lists of three health authorities from the North, Midlands and South of England. The authorities were selected to provide a diversity of location across the country and to include both urban and rural settings. To encourage participation, three reminders were sent to non-respondents and they each received a follow-up telephone call. A prize draw was used as an incentive.

\section{Data analysis}

To assess the level of change in the seven domains of practice, mean scores were calculated on level of change from the Likert scales. These were scored from 0 (non change), 1 (changed a little), 2 (changed a lot) and 3 (changed completely). The higher the score, the greater the level of reported change. Frequencies and percentages were calculated for the types of changes made. Percentages for each variable were based on the number of dentists responding to each question. Independent $t$ tests were used to test for subgroup differences in scores and univariate analysis of variance (ANOVA) was used to assess differences in more than two groups.

\section{RESULTS}

\section{Study respondents}

Of the 561 questionnaires sent out, a total of 366 (65\%) GDPs responded. Of these, 28 were sent back poorly completed or uncompleted. Data analysis was carried out on $338(60 \%)$ satisfactorily completed questionnaires. Of the responses, 54\% were from the North, 13\% from the Midlands and 33\% from the South of England (Table 1). The response rate from each of these regions was $70 \%, 52 \%$, and $53 \%$ respectively. Over half of the sample was under 40 years of age, 70\% were male and a quarter had a postgraduate qualification. One third were sole owners of their practice, $20 \%$ were partners and $46 \%$ were associates. Just under two thirds of the sample (62\%) generated less than $20 \%$ of their income from private practice.

\section{Extent of self-reported change in selected domains of practice}

Over a third of respondents reported 'changing a lot or completely" certain clinical activities, practice management arrangements and practice amenities. Mean scores for self-reported change were calculated for each of the seven domains of practice (Table 2). The highest mean score for change was for clinical activities, followed by practice management and practice amenities. The lowest mean score for change was in quality assurance and staff development.

\begin{tabular}{|c|c|c|}
\hline Characteristics & $n$ & $\%$ \\
\hline Total respondents & 338 & \\
\hline \multicolumn{3}{|l|}{ Region } \\
\hline North & 183 & 54 \\
\hline Midlands & 45 & 13 \\
\hline South & 110 & 33 \\
\hline \multicolumn{3}{|l|}{ Age } \\
\hline$<40$ years & 190 & 56 \\
\hline$>40$ years & 148 & 44 \\
\hline \multicolumn{3}{|l|}{ Sex } \\
\hline Male & 236 & 70 \\
\hline Female & 102 & 30 \\
\hline \multicolumn{3}{|c|}{ Postgraduate qualification } \\
\hline Yes & 83 & 25 \\
\hline No & 243 & 75 \\
\hline \multicolumn{3}{|l|}{ Position in practice } \\
\hline Sole owner & 112 & 33 \\
\hline Partner & 68 & 20 \\
\hline Associate & 156 & 46 \\
\hline Other & 1 & 1 \\
\hline \multicolumn{3}{|c|}{ Proportion of income generated from private practice } \\
\hline$<20 \%$ & 208 & 62 \\
\hline$>20 \%$ & 129 & 38 \\
\hline
\end{tabular}




\begin{tabular}{|c|c|c|c|c|c|c|}
\hline \multirow[b]{2}{*}{ Domain of practice } & \multicolumn{5}{|c|}{ Amount of change } & \multirow[b]{2}{*}{$95 \% \mathrm{Cl}$} \\
\hline & No change (\%) & A little (\%) & $A$ lot $(\%)$ & Completely (\%) & Mean level of change ${ }^{*}$ & \\
\hline Practice management $(n=333)$ & 20 & 40 & 33 & 6 & 1.24 & $1.13-1.32$ \\
\hline Quality assurance $(n=320)$ & 39 & 36 & 20 & 3 & 0.88 & $0.78-0.97$ \\
\hline Educational activities ( $n=332)$ & 25 & 44 & 22 & 7 & 1.11 & $1.0-1.2$ \\
\hline Clinical practices $(n=336)$ & 8 & 56 & 32 & 3 & 1.31 & $1.24-1.39$ \\
\hline Staff development $(n=332)$ & 34 & 42 & 18 & 4 & 0.92 & $0.81-0.99$ \\
\hline Communication with patients $(n=336)$ & 25 & 36 & 33 & 3 & 1.15 & $1.04-1.24$ \\
\hline Amenities $(n=327)$ & 23 & 38 & 30 & 8 & 1.24 & $1.11-1.32$ \\
\hline
\end{tabular}

\section{Nature of changes made in the seven domains of practice Clinical procedures}

The highest level of self-reported change was in clinical activities. The greatest percentage of dentists (56\%) reported an increase in preventive care, followed by crown and bridge (44\%), periodontics (44\%) and endodontics (43\%) (Fig. 1). Significant percentages of dentists reported a decrease in the amount of prosthetics (35\%), oral surgery (34\%) and orthodontics (29\%) they did now, compared with 5 years ago.

\section{Practice management}

Practice management rated second in the mean rank scores for self-reported change; 55\% changed this domain $(n=187)$. Of those respondents reporting change in their practice management procedures, 67\% had introduced computer systems and over one third had employed a practice manager (36\%).

\section{Practice amenities}

A sizeable proportion, 61\% $(n=206)$ indicated making changes to the equipment used. Of those reporting changes in equipment, 64\% said their radiographic equipment had been changed and 54\% had increased the use of new clinical equipment such as endodontic handpieces and lasers. Other changes reported included increased use of intra-oral cameras (36\%) and management equipment (21\%).

Just over half of the sample, 51\% $(n=170)$ reported making changes to their practice facilities. Of those reporting a change, $63 \%$ had redesigned their surgeries in the past five years. Forty one per cent had added an additional room, 17\% had improved patient facilities including disability access and 10\% had changed staff facilities.

\section{Communication with patients}

Two-thirds $(n=224)$ of the dentists had made changes to the way that they communicated with patients in the past five years. The greatest change (84\%) was increased information given to patients, followed by increased time spent with patients (70\%), an increase in the amount of leaflets available for patients (56\%), encouraging non-dental staff support (53\%) and provision of videos in the waiting room (6\%).

\section{Post-graduate training and professional development}

Almost all the sample, 96\% $(n=323)$ had attended some postgraduate courses in the past five years. The majority (65\%) spent between 1-30 hours and 34\% spent more than 30 hours in the past year attending courses. Respondents indicated that clinical courses were the type of training sessions which were most likely to have influenced their practices. Attendance at courses had increased for $43 \%$, and decreased for $12 \%$ of the sample in the past 5 years.

Fifty-one per cent $(n=306)$ of the GDPs reported that they met on a regular basis with dental colleagues or other professional groups. In the past 5 years, of those reporting attendance at professional groups, 37\% had increased the number of groups that they attended and $11 \%$ had decreased their attendance at such groups
The most valued sources of published educational information were Dental Practice and the British Dental Journal; 78\% and 74\% of respondents considered them important. Other sources of information included the Probe (61\%), Dental Update (55\%) and internet sites (35\%).

\section{Staff development}

Over half, 55\% ( $n=186)$ of the sample reported that they held regular meetings with all staff members where they worked. Of those who reported a change in the regularity of meetings ( $n=215), 43 \%$ had increased and 11\% had decreased the frequency of meetings in the past five years. Eighty-two per cent of the sample reported that their staff had received training in the past five years.

\section{Quality assurance activities}

Based upon reported mean scores, quality assurance activities were the area of practice least likely to have changed over a five-year period. Over half the sample, 58\% $(n=194)$ did not carry out any clinical audit or peer review activities in the past five years. A small percentage (13\%) had some experience of both clinical audit and peer review and a further $12 \%$ had carried out just clinical audit activities, and 17\% had only experience of conducting peer review.

When questioned about the details of the auditing and peer review activities, it was apparent that most of the audit activities focused on clinical techniques and materials such as endodontics and radiographic procedures. Other auditing issues covered included patient-centred audits on items such as patient waiting times or patient satisfaction with care. The types of peer review activities varied and included clinical topics, management issues, health and safety matters and patientcentred topics.

Amount of change in each domain of practice by demographic and professional characteristics

The range of changes for the seven domains studied varied between $61 \%$ and 92\%. Table 3 shows the level of change in each domain of practice by demographic and professional characteristics. Being younger was significantly related to higher reported levels of change in educational activities $(P<0.001)$, staff development $(P<0.005)$ and communication with patients $(P<0.05)$. There were no significant sex differences in the reported levels of change in each domain of practice.

Those with a postgraduate qualification scored significantly higher than those without any postgraduate qualifications in changes to practice management $(P<0.05)$; educational activities $(P<0.05)$; quality assurance $(P<0.001)$ and staff development $(P<0.001)$. Position in practice did not affect the score for change in six of the seven domains of practice, except that sole owners were significantly more likely to report a greater change in practice management than associates $(P<0.005)$. Those in a group practice were more likely to change practice management and amenities than those in a single-handed practice $(P<0.05)$. 


\begin{tabular}{|c|c|c|c|c|c|c|c|}
\hline \multirow[b]{2}{*}{ Characteristics } & \multicolumn{7}{|c|}{ Domains of practice (Mean Scores (SD) (95\% Confidence Interval)) } \\
\hline & Practice management & Quality assurance & Educational activities & Clinical practices & Staff development & $\begin{array}{l}\text { Communication } \\
\text { with patients }\end{array}$ & Amenities \\
\hline \multicolumn{8}{|l|}{ Age } \\
\hline$<40$ years & $\begin{array}{r}1.19(0.83) \\
(1.07-1.31)\end{array}$ & $\begin{array}{r}0.94(0.84) \\
(0.82-1.06)\end{array}$ & $\begin{array}{c}1.28+(0.86) \\
(1.15-1.40)\end{array}$ & $\begin{array}{c}1.35(0.67) \\
(1.26-1.45)\end{array}$ & $\begin{array}{c}1.04^{+}(0.90) \\
(0.91-1.17)\end{array}$ & $\begin{array}{r}1.25^{*}(0.85) \\
(1.13-1.37)\end{array}$ & $\begin{array}{l}1.29(0.92) \\
(1.16-1.43)\end{array}$ \\
\hline$>40$ years & $\begin{array}{r}1.31(0.87) \\
(1.17-1.45)\end{array}$ & $\begin{array}{c}0.81(0.86) \\
(0.66-0.95)\end{array}$ & $\begin{array}{c}0.90(0.86) \\
(0.76-1.04)\end{array}$ & $\begin{array}{r}1.25(0.66) \\
(1.19-1.36)\end{array}$ & $\begin{array}{r}0.77(0.72) \\
(0.65-0.89)\end{array}$ & $\begin{array}{r}1.02(0.83) \\
(0.88-1.16)\end{array}$ & $\begin{array}{l}1.17(0.89) \\
(1.03-1.32)\end{array}$ \\
\hline \multicolumn{8}{|l|}{ Sex } \\
\hline Male & $\begin{array}{r}1.26(0.84) \\
(1.15-1.37)\end{array}$ & $\begin{array}{r}0.86(0.85) \\
(0.75-0.97)\end{array}$ & $\begin{array}{r}1.08(0.86) \\
(0.97-1.19)\end{array}$ & $\begin{array}{r}1.30(0.67) \\
(1.22-1.39)\end{array}$ & $\begin{array}{r}0.92(0.86) \\
(0.81-1.03)\end{array}$ & $\begin{array}{r}1.15(0.86) \\
(1.04-1.26)\end{array}$ & $\begin{array}{c}1.19(0.89) \\
(1.08-1.31)\end{array}$ \\
\hline Female & $\begin{array}{r}1.21(0.88) \\
(1.04-1.38)\end{array}$ & $\begin{array}{r}0.95(0.85) \\
(0.77-1.12)\end{array}$ & $\begin{array}{r}1.20(0.90) \\
(1.02-1.38)\end{array}$ & $\begin{array}{r}1.33(0.65) \\
(1.20-1.46)\end{array}$ & $\begin{array}{r}0.94(0.80) \\
(0.78-1.10)\end{array}$ & $\begin{array}{r}1.17(0.82) \\
(1.01-1.33)\end{array}$ & $\begin{array}{c}1.35(0.94) \\
(1.16-1.54)\end{array}$ \\
\hline \multicolumn{8}{|c|}{ Postgraduate qualifications } \\
\hline Yes & $\begin{array}{r}1.43^{*}(0.86) \\
(1.25-1.62)\end{array}$ & $\begin{array}{c}1.20^{\ddagger}(0.87) \\
(1.01-1.40)\end{array}$ & $\begin{array}{c}1.30 *(0.89) \\
(1.11-1.50)\end{array}$ & $\begin{array}{r}1.42(0.70) \\
(1.27-1.57)\end{array}$ & $\begin{array}{c}1.22^{\ddagger}(0.94) \\
(1.01-1.43)\end{array}$ & $\begin{array}{r}1.23(0.84) \\
(1.05-1.42)\end{array}$ & $\begin{array}{c}1.29(0.85) \\
(1.10-1.48)\end{array}$ \\
\hline No & $\begin{array}{r}1.21(0.83) \\
(1.10-1.31)\end{array}$ & $\begin{array}{r}0.77(0.81) \\
(0.66-0.87)\end{array}$ & $\begin{array}{r}1.06(0.87) \\
(0.95-1.17)\end{array}$ & $\begin{array}{r}1.27(0.65) \\
(1.19-1.36)\end{array}$ & $\begin{array}{r}0.82(0.76) \\
(0.73-0.92)\end{array}$ & $\begin{array}{r}1.13(0.84) \\
(1.02-1.23)\end{array}$ & $\begin{array}{l}1.21(0.92) \\
(1.09-1.32)\end{array}$ \\
\hline \multicolumn{8}{|c|}{ Position in practice } \\
\hline Sole owner & $\begin{array}{c}1.32^{\dagger}(0.82) \\
(1.17-1.48)\end{array}$ & $\begin{array}{c}0.91(0.82) \\
(0.76-1.07)\end{array}$ & $\begin{array}{c}0.98(0.87) \\
(0-82-1.14)\end{array}$ & $\begin{array}{r}1.32(0.65) \\
(1.19-1.44)\end{array}$ & $\begin{array}{r}0.94(0.82) \\
(0.78-1.09)\end{array}$ & $\begin{array}{r}1.14(0.89) \\
(0.98-1.31)\end{array}$ & $\begin{array}{l}1.22(0.92) \\
(1.05-1.39)\end{array}$ \\
\hline Partner & $\begin{array}{c}1.52^{\dagger}(0.85) \\
(1.31-1.72)\end{array}$ & $\begin{array}{r}1.02(0.98) \\
(0.77-1.26)\end{array}$ & $\begin{array}{c}1.11(0.90) \\
(0.89-1.33)\end{array}$ & $\begin{array}{r}1.40(0.78) \\
(1.21-1.59)\end{array}$ & $\begin{array}{r}1.03(0.76) \\
(0.84-1.22)\end{array}$ & $\begin{array}{r}0.96(0.84) \\
(0.75-1.16)\end{array}$ & $\begin{array}{l}1.34(0.89) \\
(1.12-1.56)\end{array}$ \\
\hline Associate & $\begin{array}{r}1.08(0.84) \\
(0.94-1.21)\end{array}$ & $\begin{array}{c}0.81(0.81) \\
(0.68-0.94)\end{array}$ & $\begin{array}{r}1.21(0.87) \\
(1.08-1.35)\end{array}$ & $\begin{array}{r}1.26(0.62) \\
(1.16-1.36)\end{array}$ & $\begin{array}{c}0.86(0.87) \\
(0.72-1.01)\end{array}$ & $\begin{array}{r}1.24(0.81) \\
(1.12-1.37)\end{array}$ & $\begin{array}{l}1.21(0.91) \\
(1.07-1.36)\end{array}$ \\
\hline \multicolumn{8}{|l|}{ Type of practice } \\
\hline Single-handed & $\begin{array}{r}1.05(0.84) \\
(0.81-1.19)\end{array}$ & $\begin{array}{r}0.88(0.87) \\
(0.88-1.26)\end{array}$ & $\begin{array}{r}1.08(0.90) \\
(0.68-1.06)\end{array}$ & $\begin{array}{r}1.30(0.69) \\
(0.92-1.31)\end{array}$ & $\begin{array}{r}0.92(0.85) \\
(1.14-1.44)\end{array}$ & $\begin{array}{r}1.11(0.88) \\
(0.71-1.08)\end{array}$ & $\begin{array}{l}1.01(0.89) \\
(0.90-1.28)\end{array}$ \\
\hline Group & $\begin{array}{c}1.32^{*}(0.84) \\
(1.20-1.41)\end{array}$ & $\begin{array}{c}0.89(0.85) \\
(0.78-1.01)\end{array}$ & $\begin{array}{r}1.11(0.87) \\
(1.01-1.21)\end{array}$ & $\begin{array}{r}1.33(0.65) \\
(1.24-1.41)\end{array}$ & $\begin{array}{r}0.92(0.83) \\
(0.83-1.04)\end{array}$ & $\begin{array}{r}1.12(0.84) \\
(1.06-1.27)\end{array}$ & $\begin{array}{l}1.31^{*}(0.90) \\
(1.20-1.43)\end{array}$ \\
\hline \multicolumn{8}{|c|}{$\%$ Private practice } \\
\hline$<20 \%$ & $\begin{array}{r}1.11(0.85) \\
(1.01-1.23)\end{array}$ & $\begin{array}{r}0.77(0.79) \\
(0.66-0.88)\end{array}$ & $\begin{array}{r}1.03(0.84) \\
(0.92-1.15)\end{array}$ & $\begin{array}{r}1.19(0.64) \\
(1.10-1.28)\end{array}$ & $\begin{array}{r}0.83(0.80) \\
(0.72-0.94)\end{array}$ & $\begin{array}{r}1.01(0.82) \\
(0.90-1.12)\end{array}$ & $\begin{array}{l}1.17(0.93) \\
(1.04-1.30)\end{array}$ \\
\hline$>20 \%$ & $\begin{array}{r}\left.1.46^{\ddagger} 0.81\right) \\
(1.31-1.60)\end{array}$ & $\begin{array}{r}1.07^{+}(0.92) \\
(0.90-1.23)\end{array}$ & $\begin{array}{l}1.24^{*}(0.92) \\
(1.07-1.40)\end{array}$ & $\begin{array}{r}1.50^{\ddagger}(0.66) \\
(1.39-1.62)\end{array}$ & $\begin{array}{r}1.07^{*}(0.87) \\
(0.92-1.22)\end{array}$ & $\begin{array}{r}1.38^{\ddagger}(0.84) \\
(1.24-1.53)\end{array}$ & $\begin{array}{l}1.34(0.86) \\
(1.19-1.50)\end{array}$ \\
\hline \multicolumn{8}{|l|}{ Location } \\
\hline North & $\begin{array}{r}1.24(0.84) \\
(1.11-1.36)\end{array}$ & $\begin{array}{r}0.83(0.81) \\
(0.71-0.95)\end{array}$ & $\begin{array}{c}1.09^{+}(0.86) \\
(0.96-1.21)\end{array}$ & $\begin{array}{r}1.19(0.62) \\
(1.11-1.28)\end{array}$ & $\begin{array}{r}0.93(0.87) \\
(0.81-1.06)\end{array}$ & $\begin{array}{r}1.00^{\dagger}(0.80) \\
(0.88-1.12)\end{array}$ & $\begin{array}{l}1.29^{*}(0.94) \\
(1.15-1.43)\end{array}$ \\
\hline Midlands & $\begin{array}{c}1.48(0.90) \\
(1.20-1.75)\end{array}$ & $\begin{array}{r}(0.85-1.44) \\
1.14(0.95)\end{array}$ & $\begin{array}{r}(0.94-1.52) \\
1.23(0.96)\end{array}$ & $\begin{array}{r}(1.28-1.74) \\
1.51(0.76)\end{array}$ & $\begin{array}{l}(0.82) \\
(0.75-1.25)\end{array}$ & $\begin{array}{r}1.38(0.91) \\
(1.10-1.65)\end{array}$ & $\begin{array}{l}1.50(0.98) \\
(1.20-1.80)\end{array}$ \\
\hline South & $\begin{array}{r}1.16(0.84) \\
(1.01-1.32)\end{array}$ & $\begin{array}{r}0.87(0.87) \\
(0.70-1.03)\end{array}$ & $\begin{array}{r}1.10(0.87) \\
(0.94-1.27)\end{array}$ & $\begin{array}{r}1.43(0.66) \\
(1.30-1.55)\end{array}$ & $\begin{array}{r}0.88(0.78) \\
(0.73-1.03)\end{array}$ & $\begin{array}{r}1.31(0.86) \\
(1.15-1.48)\end{array}$ & $\begin{array}{l}1.05(0.78) \\
(0.91-1.19)\end{array}$ \\
\hline
\end{tabular}

${ }^{*} P<0.05 ;{ }^{\dagger} P<0.005 ;{ }^{\ddagger} P<0.001$ : Maximum score in each domain of practice $=3$

The practice characteristics that made the biggest difference in levels of self-reported change was the proportion of private practice. Those with greater than 20\% private practice were significantly more likely to report higher levels of change in practice management, clinical practices, communication with patients $(P<0.001)$, quality assurance $(P<0.005)$ and educational and staff development $(P<0.05)$. There were no differences in changes to amenities by the amount of private practice. There were significant differences in amount of change in educational activities and staff development $(P<0.005)$ and amenities $(P<0.05)$, between the geographical areas (Table 3).

\section{DISCUSSION}

The results of this study provide an interesting overview of the extent and nature of self reported change amongst a sample of English GDPs. A large percentage of respondents had changed the way they practiced over a relatively short time period. GDPs' work patterns appear to be dynamic and changing. The variation in the levels of change across the domains of practice investigated is also noteworthy. The largest change was in types of clinical procedures being carried out. About half of the practitioners reported increasing their provision of preventive care. Additionally, 44\% said they had increased the amount of crown and bridgework, periodontal treatment and endodontic care. On the other hand considerable numbers reported reductions in the amounts of prosthetics and oral surgery activity. These changes in clinical care match recent trends in oral health in the United Kingdom, ${ }^{21}$ and suggest that GDPs are responding to the changing oral health needs of the population.

There were notable levels of change in practice management, and in changes to the practice amenities and facilities. These no doubt reflect the increasing emphasis being placed on management systems and the need for modern practice premises. In addition, a sizeable proportion of practitioners reported making changes in communication with their patients. Providing more information and spending more time explaining treatments to patients are encouraging developments. All these self-reported changes are very much in line with the recommendations within Options for Change. ${ }^{3}$

A very high proportion of respondents attended postgraduate courses in the previous five years. Indeed, over one third of the dentists surveyed were spending more than 30 hours per year on courses, and attendance at postgraduate courses had increased for almost half of respondents. These findings support the results of a recent Scottish study assessing patterns of continuing professional development amongst primary care dentists. ${ }^{22}$

The positive findings in relation to continuing professional development are in contrast to the rather disappointing results for quality assurance activities such as audit and peer review, where the level of involvement was relatively low and did not appear to be changing. The current recommendations on expanding peer review and clinical audit within the General Dental Services (GDS) need to recognise the lack of engagement by many practitioners in these activities. ${ }^{2}$ 
Significant differences were found between certain professional and personal characteristics in the sample. Those dentists who earned more than $20 \%$ of their income from private practice reported higher levels of change in six aspects of practice. The perceived pace of work in practices with larger proportions of NHS dental patients is greater. ${ }^{23}$ Therefore it may be the increased time available, rather than the source of income that leads to a greater degree of change among those with more private practice. This increase in time in private dental practice may also be related to continuing professional education and time to participate in other activities. Changing to private practice may also mean raised patient expectations, which necessitates change.

Those dentists who had a postgraduate qualification also reported higher levels of change in four aspects of practice. One of the aspects of practice where postgraduate qualification made a difference was quality assurance, which includes audit and peer review activities. This could be related to having more contact with other professionals, a factor related to change in medical practice. ${ }^{5}$ In dentistry, integration into the dental community was related to adoption of specific techniques, ${ }^{9}$ and postgraduate education may be one way in which this integration occurs.

Being younger was significantly related to higher reported levels of change in educational activities, staff development and communication with patients. Age has been reported to be related to levels of change in medical practice. ${ }^{6,7}$ This study however found no significant relationship between the sex of the dentist and levels of self reported change.

Assessing change in human behaviour is difficult. In accordance with research into changes made by general medical practitioners, ${ }^{24-26}$ this study assessed change within general dental practice based upon self reports. Such an approach has some limitations. Self-reported change may not correspond with actual changes made. In this study the questionnaire used to assess self reported change was developed and tested to ensure that the respondents would not feel the need to give a certain response, thereby minimising responder bias. The fact that the changes in the amounts of clinical procedures reported by dentists in this study is similar to treatment trends reported by the Dental Practice Board and other researchers suggests that the responses given to our survey were reasonably accurate. ${ }^{27,28}$ Another potential weakness of the study is the relatively low overall response rate and the

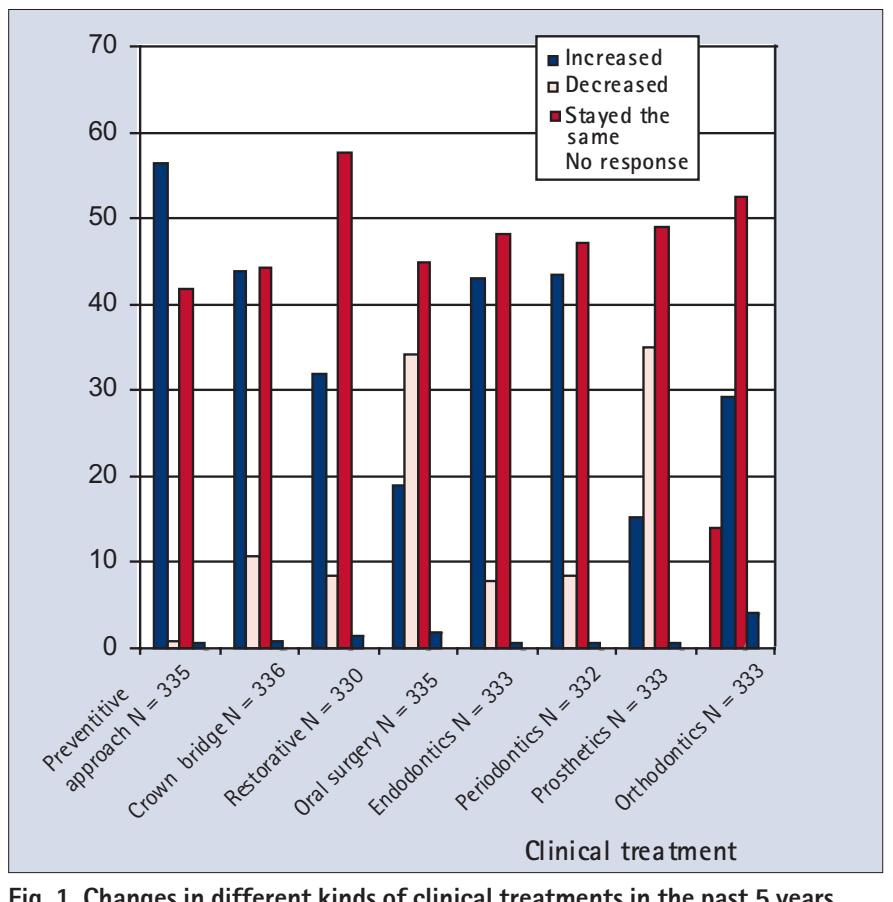

Fig. 1 Changes in different kinds of clinical treatments in the past 5 years possible bias this may have introduced. In two of the three study locations, age and sex differences between responders and non responders was assessed and found to be very similar. In addition, the age and sex profile of the sample was compared with national Dental Practice Board figures. A very similar sex profile was found, although a slightly higher proportion of the sample (56\%) was under the age of 40 years compared with the national figure (49\%). The results of this study cannot therefore be seen as representative of GDPs across the country as a whole.

In conclusion, it is apparent that significant levels of change took place in several domains of general dental practice in three regions of England over a 5-year period. The self-reported changes indicate some encouraging trends and highlight dental practitioners' willingness to respond to changing needs and demands on their service.

This study was funded through the Primary Dental Care $R$ \& $D$ Programme. The authors would like to thank all the general dental practitioners who participated in this study.

1. Department of Health. The NHS Plan. London: The Stationery Office, 2000

2. Department of Health. Modernising NHS Dentistry-Implementing the NHS Plan. London: Department of Health, 2000.

3. Department of Health. NHS Dentistry: Options for Change. London: Department of Health, 2002.

4. Oxman A, Thomson M, Davis D, Haynes R. No magic bullets: a systematic review of 102 trials of interventions to improve professional practice. Can MedJ 1995; 153: 14231431.

5. Allery L, Owen P, Robling M. Why general practitioners and consultants change their clinical practice: a critical incident study. Br Med J 1997; 314: 870-879.

6. Salisbury C, Bosanquet N, Wilkinson E, Bosanquet A, Hasler J. The implementation of EBM in general practice prescribing. Br J Gen Prac 1998; 437: 1849-1852.

7. Weiss $R$, Charney $E$, Baumgardner $R$, et al. Changing patient management: what influences the practicing pediatrician? Pediatr 1990; 85: 791-795.

8. Hunt R, Kohout F. Predicting the adoption of pit and fissure sealants. J Dent Res 1983: 62: 234 .

9. Frazier J. Public and Professional adoption of selected methods to prevent dental decay. In: Cohen L, Bryant P. (ed) Social sciences and dentistry: A critical bibliography. London: Quintessence Publishing Company, 1984.

10. Main $P$, Lewis D, Hawkins R. A survey of general dentists in Ontario, part 1: sealant use and knowledge. J Can Dent Assoc 1997; 63: 545-553.

11. Holloway P. Clarkson J. Cost: benefit of prevention in practice. Int Dent J 1994; 4: 317-322.

12. Kay E, Nuttall N. Relationship between dentists' treatment attitudes and restorative decisions made on the basis of simulated bitewing radiographs. Community Dent Oral Epidemiol 1994; 22: 71-74.

13. Gift $H$, Frew $R$, Hefferren J. Attitudes and use of pit and fissure sealants. J Dent Child 1975; 43: 460-466.

14. Davis P. The social context of dentistry. London: Croom Helm, 1980.

15. Kay E, Blinkhorn A. A qualitative investigation of factors governing dentists' treatment philosophies. Br Dent J 1996; 180: 171-176.

16. Rushton $\mathrm{V}$, Horner $\mathrm{K}$, Worthington $\mathrm{H}$. Factors influencing the frequency of bitewing radiography in general dental practice. Community Dent Oral Epidemiol 1996; 24: 272-276.

17. Freeman R. Barriers to accessing dental care: patient factors. Br Dent J1999; 187: 141-144.

18. Chapko M. Time to adoption of an innovation by dentists in private practice: sealant utilization. J Pub Health Dent 1991; 51: 144-151.

19. Svenson B, Grondahl H, Soderfeldt B. A logistic regression model for analyzing the relation between dentists' attitudes, behaviour and knowledge in oral radiology. Acto Odontol Scand 1998; 56: 215-219.

20. Jick T. Mixing qualitative and quantitative methods: triangulation in action. Admin Sc Quart 1979; 24: 602-611.

21. Kelly M, Steele J, Nuttall N, et al. Adult Dental Health Survey: Oral health in the United Kingdom 1998. London: The Stationery Office, 2000

22. Leggate $M$, Russell E. Attitudes and trends of primary care dentists to continuing professional development: a report from the Scottish dental practitioners survey 2000. Br Dent J 2002; 193: 465-469.

23. Silvester $S$, Calnan M, Taylor-Gooby P, Manley G. Dentistry: filling in time. Health Serv J 1999; 109: 22-23.

24. Wilson $R$, Buchan I, Walley T. Alterations in prescribing by general practitioner fund holders: an observational study. Br Med J 1995; 311:347-1359.

25. Stewart-Brown S, Surender R, Bradlow J, Coulter A, Doll H. The effects of fundholding in general practice on prescribing habits three years after introduction. BrMed J 1995; 311: 1543-1547.

26. Armstrong $D$, Reyburn $H_{1}$ Jones R. A study of general practitioners' reasons for changing their prescribing behaviour. Br Med J 1996; 312: 949-952.

27. Dental Practice Board. Dental Treatment:GDS Annual Statistics. April 1999-March 2000. England and Wales. Dental Practice Board, 2000.

28. McCaul L, Jenkins W, Kay E. The reasons for extractions of permanent teeth in Scotland: a 15-year follow-up study. Br Dent J2001; 190: 658-662. 